Address for Correspondence: Dr. Gianluca Rigatelli, MD, PhD, EBIR, FACP, FACC, FESC, FSCAI, Cardiovascular Diagnosis and Endoluminal Interventions, Rovigo General Hospital, Rovigo 45100, Italy. Email: jackyheart71@yahoo.it

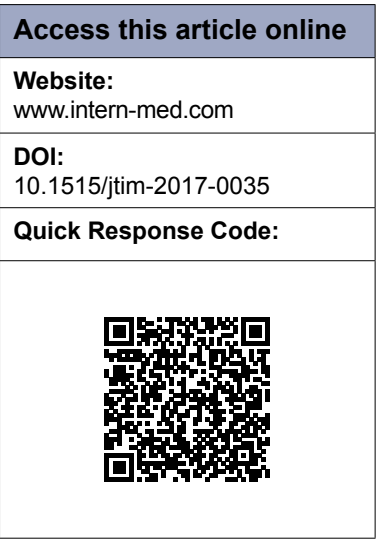

\title{
Comparative computed flow dynamic analysis of different optimization techniques in left main either provisional or culotte stenting
}

\author{
Gianluca Rigatelli' ${ }^{1}$, Fabio Dell'Avvocata ${ }^{1}$, Marco Zuin ${ }^{1}$, Sara Giatti ${ }^{1}$, \\ Khanh Duong', Trung Pham², Nguyen Si Tuan², Dobrin Vassiliev ${ }^{3}$, \\ Ramesh Daggubati ${ }^{4}$, Thach Nguyen ${ }^{5}$ \\ 'Section of Cardiovascular Diagnosis and Endoluminal Interventions, Rovigo General Hospital, Rovigo, Italy; \\ ${ }^{2}$ Tan Tao University, School of Medicine, Long An, Vietnam; \\ ${ }^{3}$ Department of Cardiology; Alexandrovska University School of Medicine, Sofia, Bulgaria; \\ ${ }^{4}$ Cardiac Catheterization Laboratories, Winthrop University Hospital Mineola, NY, USA; \\ ${ }^{5}$ Cardiovascular Research, Methodist Hospital, Merrillville, IN, USA
}

\begin{abstract}
Background and Objectives: Provisional and culotte are the most commonly used techniques in left main (LM) stenting. The impact of different post-dilation techniques on fluid dynamic of LM bifurcation has not been yet investigated. The aim of this study is to evaluate, by means of computational fluid dynamic analysis (CFD), the impact of different post-dilation techniques including proximal optimization technique (POT), kissing balloon (KB), POT-Side-POT and POT-KB-POT, 2-steps Kissing (2SK) and Snuggle Kissing balloon (SKB) on flow dynamic profile after LM provisional or culotte stenting. Methods: We considered an LM-LCA-LCX bifurcation reconstructed after reviewing 100 consecutive patients (mean age $71.4 \pm 9.3$ years, 49 males) with LM distal disease. The diameters of LAD and LCX were modelled according to the Finnet's law as following: LM $4.5 \mathrm{~mm}$, LAD $3.5 \mathrm{~mm}$, LCX $2.75 \mathrm{~mm}$, with bifurcation angle set up at $55^{\circ}$. Xience third-generation stent (Abbot Inc., USA) was reconstructed and virtually implanted in provisional/cross-over and culotte fashion. POT, KB, POT-side-POT, POT-KB-POT, 2SK and SKB were virtually applied and analyzed in terms of the wall shear stress (WSS). Results: Analyzing the provisional stenting, the $2 \mathrm{SK}$ and KB techniques had a statistically significant lower impact on the WSS at the carina, while POT seemed to obtain a neutral effect. In the wall opposite to the carina, the more physiological profile has been obtained by KB and POT with higher WSS value and smaller surface area of the lower WSS. In culotte stenting, at the carina, POT-KB-POT and 2SK had a very physiological profile; while at the wall opposite to the carina, 2SK and POT-KB-POT decreased significantly the surface area of the lower WSS compared to the other techniques. Conclusion: From the fluid dynamic point of view in LM provisional stenting, POT, 2SK and KB showed a similar beneficial impact on the bifurcation rheology, while in LM culotte stenting, POT-KB-POT and 2SK performed slightly better than the other techniques, probably reflecting a better strut apposition.
\end{abstract}

Key words: left main stenting, stenting techniques; computational fluid dynamic analysis

\section{INTRODUCTION}

During crossover/provisional left main (LM) stenting, final kissing balloon inflation (KBI), with simultaneous inflation of the main vessel (MV) and side branch (SB) balloons, has been thought to be most effective in order to secure SB patency, reduce $\mathrm{SB}$ stenosis and remove jailed struts. ${ }^{[1]}$

The advantage of KBI over non-KBI treatment in terms of major adverse cardiac events (MACE), has not been proven despite lower SB diameter stenosis at a six to 12 -month follow-up. ${ }^{[2-3]}$ On the other hand, proximal optimization technique 
(POT), which is a dilation of the MV proximal to the carina, has been proved to correct the proximal MV malapposition and optimize SB ostium strut opening for proper wire re-crossing in the distal cell. ${ }^{[4]}$ Modifications of both techniques have been proposed in order to achieve a bigger SB ostium with low MV distortion and malapposition. These new techniques include the sequential POT-side-POT as alternative to KB, ${ }^{[5]}$ the POT-KB-POT, ${ }^{[6]}$ the 2-step kissing $(2 \mathrm{SK})^{[]]}$and the snuggle $\mathrm{KB}(\mathrm{SKB})$ or T-ballooning. ${ }^{[8]}$

The exact hemodynamic value of these new techniques has not been investigated in the standard coronary artery bifurcation. Which is the ideal technique in the LM bifurcation scenario independent of the provisional or dual stenting techniques? As designing a randomized trial evaluating the outcomes of such different techniques in a homogeneous population of LM disease is conceptually impossible and economically expensive, computational fluid dynamic (CFD) analysis, ${ }^{[9]}$ which has been applied in many fields of cardiovascular medicine, may give at least a suggestion on the impact of such techniques on flow physiology and may represent the basis for further in-vivo investigation. The aim of the study is to evaluate by CFD the impact of provisional single-stenting or culotte dualstenting on flow dynamic of LM bifurcation and LAD/ LCX ostia.

\section{MATERIAL AND METHODS}

\section{Left main model}

For the computational domain analysis, we considered a LM-LCA-LCX bifurcation reconstructed after analyzing 100 consecutive patients (mean age $71.4 \pm 9.3$ years, 49 males) with LM distal disease, who underwent percutaneous coronary intervention (PCI) between January 1 $1^{\text {st }}, 2016$ and January $1^{\text {st }}, 2017$. The mean diameter of the proximal LM, LAD and LCX by quantitative coronary analysis (QCA) was $4.62 \pm 0.86 \mathrm{~mm}, 3.31 \pm 0.92 \mathrm{~mm}$, and $2.74 \pm$ $0.93 \mathrm{~mm}$, respectively. The mean LAD-LCX bifurcation angle, measured after the diagnostic angiography using an electronic goniometer was $53.6^{\circ} \pm 12.3^{\circ}$, whereas the mean length of LM was $19.4 \pm 4.1 \mathrm{~mm}$ (Figure 1). The mean diameter stenosis by QCA was $82 \% \pm 7.6 \%$. The diameter of the ascending aorta at the origin of the left coronary artery was $28 \pm 4.7 \mathrm{~mm}$. The diameters of LAD and LCX were modelled according to the Finnet's law ${ }^{[10]}$ resembling the in-vivo measurements, as following: LM $4.5 \mathrm{~mm}$, LAD $3.5 \mathrm{~mm}$, LCX $2.75 \mathrm{~mm}$, with bifurcation angle set up at $55^{\circ}$. The LM was divided into three sections including ostium, mid-shaft and distal portion. A plaque inducing a stenosis of $90 \%$ was placed at the mid-shaft/distal position (Figure 1). The model was constructed using Rhinoceros v. 4.0 Evaluation (McNeel \& Associates, Indianapolis, IN). Pressure was assumed to be stable at 120/80 mmHg.
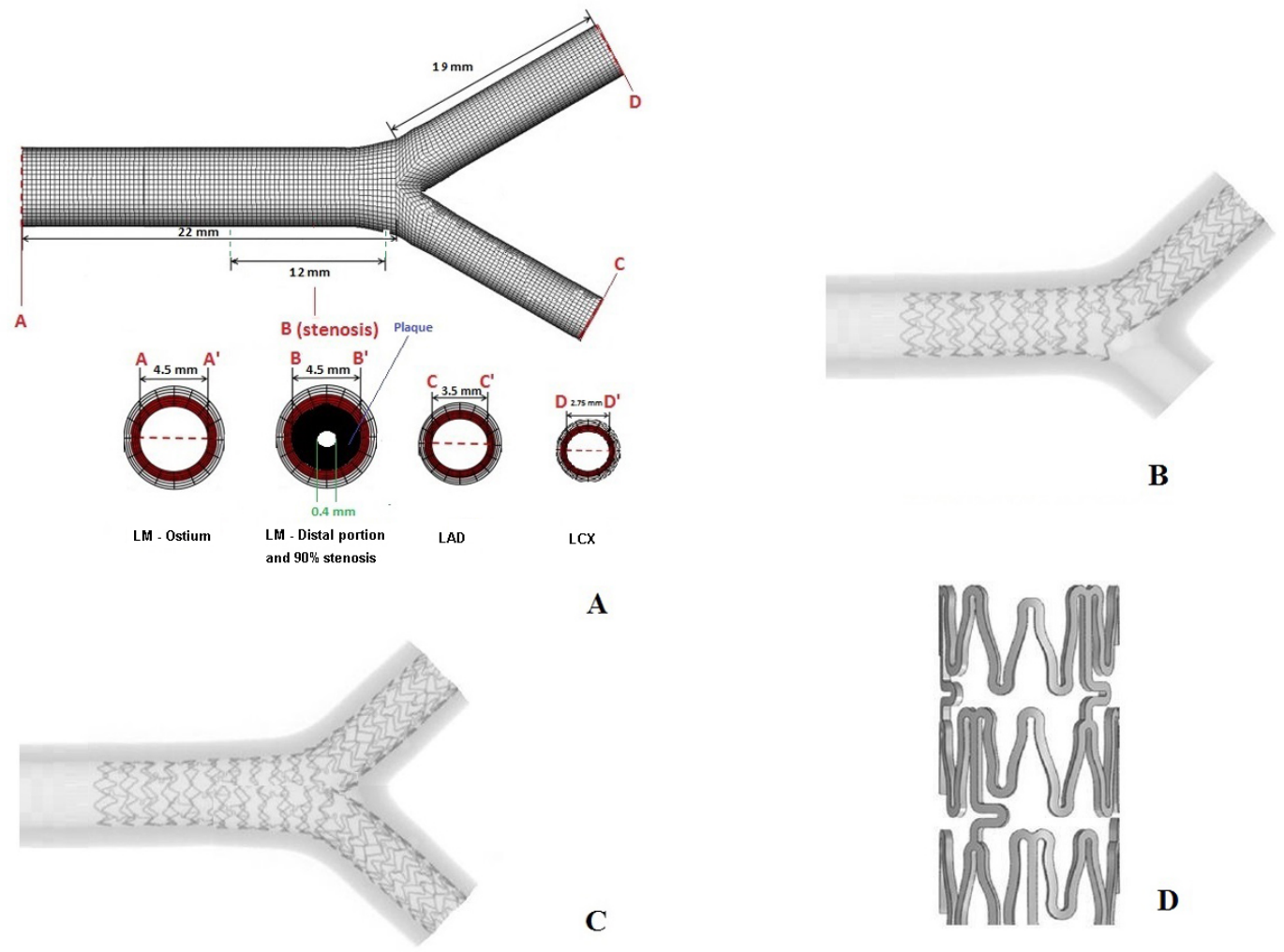

A

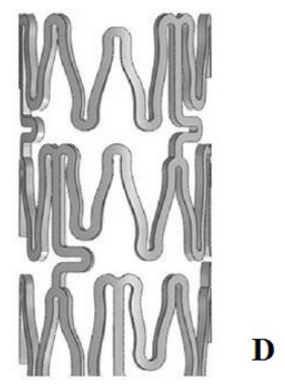

Figure 1: Left main coronary artery bifurcation model: A) model diameter and length; B) Appearance of the virtual implantation of Xience in provisional stenting fashion; C) Appearance of the virtual implantation of Xience in culotte fashion; D) Xience design and reconstruction. 


\section{Stent simulation}

For the stent simulation, we reconstructed the strut design and linkage pattern of a third-generation, everolimuseluting stent ( Xience, Abbot Corp, USA), used in our institution. Computer Aided Design (CAD) software was used to reproduce the stented geometry as accurately as possible (SolidWorks 2009, SolidWorks Corp, Concord, $\mathrm{MA}$ ). At first, we created the solid model of the coronary artery bifurcation and then the expanded stent geometry (Figure 1). For this purpose, a hollow tube with outer diameter equal to both the nominal expanded diameter and thickness of the stent was created. Then, a 2-dimensional sketch with the stent's strut was propagated and wrapped around the tube. Through a cut-out, the obtained ring of the stent was propagated axially to create a full-length, expanded model.

\section{Interventional protocols adopted in the simulation}

Cross-over/provisional stenting: 1) Predilation of MV 1:1 with non-compliant balloon; and 2) Stenting of MV with stent diameter according to the distal MV reference diameter as currently recommended. ${ }^{[11]}$

Culotte stenting: 1) Predilation of both branches 1:1 with non-compliant balloon; 2) Stenting of MV to SB; 3) Opening the stent cell with small $2.0 \times 15 \mathrm{~mm}$ balloon; and 4) Stenting MB proximal to distal.

Steps for different post-dilation techniques are reported in Table 1. Only POT was not considered in the analysis of culotte stenting because it is not used in clinical practice in dual stenting.

\section{Virtual Implantation}

After the stent model was placed in the correct position as per the different stenting techniques, material removal was applied depending on the considered techniques. Subsequently, using the Boolean operation, the modified solid model was subtracted from the bifurcation model to obtain the final geometry. Specifically, we assumed that after stent deployment and implantation, both in the main and side branch, there were no residual stenosis.

\section{CFD analysis}

To analyze the spatially resolved velocity, pressure and wall shear stress (WSS), we used CFD simulations. In particular, we modelled blood as a non-Newtonian, viscous and incompressible fluid. Density was defined as $1060 \mathrm{~kg} /$ $\mathrm{m}^{3}$, according to the standard values cited in the literature. Blood was represented by the Navier-Stokes equation:

$$
\mathrm{v} \cdot \nabla \mathrm{v}=-\nabla \cdot \tau-\nabla P
$$

and continuity equation:

$$
\nabla \cdot \mathrm{v}=0
$$

where $\mathrm{v}$ is the $3 \mathrm{D}$ velocity vector, $\mathrm{P}$ pressure, $\mathrm{r}$ density and $\tau$ the shear stress term. Instead, Carreau model was adopted for viscosity:

$$
\begin{aligned}
& \mu=\mu_{\infty}+\left(\mu_{0}-\mu_{\infty}\right)\left[1+(\lambda \dot{\gamma})^{2}\right]^{\frac{(n-1)}{2}}, \\
& \text { where } \lambda=3.313 s, n=0.3568, \mu_{0} \\
& =0.56 P \text { and } \mu_{\infty}=0.0345 P
\end{aligned}
$$

\begin{tabular}{|c|c|c|c|}
\hline & Steps & & \\
\hline Techniques & 1 & 2 & 3 \\
\hline POT & $\begin{array}{l}\text { Inflation of SC balloon } \\
4.5 \times 6 \mathrm{~mm} \text { at } 20 \mathrm{~atm}\end{array}$ & & \\
\hline$\overline{K B}$ & $\begin{array}{l}\text { Inflation of the SB with SC balloon } \\
2.0 \times 15 \mathrm{~mm} \text { at } 16 \text { atm }\end{array}$ & $\begin{array}{l}\text { Simultaneous inflation of } 3.5 \times 15 \\
(\mathrm{LM} \text { to } \mathrm{LAD} \text { ) e } 2.75 \times 15 \mathrm{~mm} \text { (LM to } \\
\mathrm{LCX} \text { ) SC balloons at } 18 \mathrm{~atm}\end{array}$ & \\
\hline РOT -Side-POT & $\begin{array}{l}\text { Inflation of SC balloon } 4.5 \times 6 \mathrm{~mm} \\
\text { at } 20 \mathrm{~atm}\end{array}$ & $\begin{array}{l}\text { Inflation of } 2.75 \times 15 \mathrm{~mm} \text { (LM to } \\
\mathrm{LCX} \text { ) NC balloon at } 18 \mathrm{~atm}\end{array}$ & $\begin{array}{l}\text { Inflation of SC } 4.5 \times 6 \mathrm{~mm} \text { balloon } \\
\text { at } 20 \mathrm{~atm}\end{array}$ \\
\hline РОТ-КВ-РОТ & $\begin{array}{l}\text { Inflation of SC balloon } 4.5 \times 6 \mathrm{~mm} \\
\text { at } 20 \mathrm{~atm}\end{array}$ & $\begin{array}{l}\text { Simultaneous inflation of } 3.5 \times 15 \\
(\mathrm{LM} \text { to } \mathrm{LAD} \text { ) e } 2.75 \times 15 \mathrm{~mm}(\mathrm{LM} \text { to } \\
\mathrm{LCX}) \mathrm{SC} \text { balloons at } 18 \mathrm{~atm}\end{array}$ & $\begin{array}{l}\text { Inflation of SC balloon } 4.5 \times 6 \mathrm{~mm} \\
\text { at } 20 \mathrm{~atm}\end{array}$ \\
\hline 2SK & $\begin{array}{l}\text { Inflation of the SB with SC balloon } \\
2.0 \times 15 \mathrm{~mm} \text { at } 16 \text { atm }\end{array}$ & $\begin{array}{l}\text { Inflation of } 3.5 \times 15 \text { (LM to LAD) SC } \\
\text { balloon at } 18 \mathrm{~atm}\end{array}$ & $\begin{array}{l}\text { Inflation of } 2.75 \times 15 \mathrm{~mm} \text { (LM to } \\
\text { LCX) SC balloon at } 18 \mathrm{~atm}\end{array}$ \\
\hline SKB & $\begin{array}{l}\text { Simultaneous inflation of } 3.5 \times 15 \\
\text { (LM to LAD) e } 2.75 \times 15 \mathrm{~mm} \text { (LM } \\
\text { to LCX) SC balloons at } 18 \text { atm with } \\
\text { the marker of the SB balloon at the } \\
\text { middle of the MB balloon }\end{array}$ & & \\
\hline
\end{tabular}

Given that coronary artery perfusion is primarily diastolic, at the inlet we considered a steady blood flow velocity $(0.18 \mathrm{~m} / \mathrm{s})$

Table 1: Steps for each technique included in the computational analysis

LAD: left anterior descending coronary artery; LCX: left circumflex coronary artery; LM: left main; KB: kissing balloon; POT: proximal optimization technique; SKB: snuggle kissing balloon; 2SK: 2-step sequential kissing balloon; atm: atmosphere 
and pressure $(10,665 \mathrm{~Pa}$ equivalent to $80 \mathrm{mmHg}) .^{[12,14]}$ The hemodynamic parameters that were assessed at stented LM bifurcation were static pressure $(\mathrm{Pa})$, WSS $(\mathrm{Pa})$ and area of lower WSS $\left(\mathrm{cm}^{2}\right)$ through the carina, which is one of the most sensible site for restenosis/thrombosis in coronary bifurcation. ${ }^{[15]}$ The numeric grid was created from the geometry using ANSYS Meshing 14.0 (Ansys, Inc., Canonsburg, PA), while the simulations were conducted using the commercial software ANSYS FLUENT 14.0 (Ansys, Inc., Canonsburg, PA).

\section{Fluid parameters}

Static and dynamic pressure in the vessel was evaluated in Pascal. Practically, low static pressure is generally related to an increased vessel wall thickness. ${ }^{[16]}$ In particular, dynamic pressure has been defined as:

$$
q \equiv \frac{1}{2} v^{2}
$$

Wall shear stress $(\mathrm{Pa})$ has been defined as the force that is tangentially acting to the surface due to friction. As it is well known, low wall shear stress is related to the development of greater plaque and necrotic core progression with a constrictive remodeling, whereas high wall shear stress segment develops greater necrotic core and calcium progression with expansive remodeling. ${ }^{[17-18]}$

\section{RESULTS}

\section{Provisional stenting analysis}

The 2SK and $\mathrm{KB}$ techniques resulted in a statistically significant lower impact on the WSS at both LAD/LCX ostia and a surface area with lower WSS at the carina. These results were very similar to the physiologic model (233 and $254 \mathrm{~mm}^{2}$, respectively $v$ s. $202 \mathrm{~mm}^{2}, P=0.03$ and $P=0.001$, while POT resulted in a neutral effect. On the contrary, POT-side-POT, POT-KB-POT and SKB had the worst physiologic profile (Table 2, Figure 2).

\begin{tabular}{|c|c|c|c|c|c|c|c|}
\hline & $\begin{array}{l}\text { Pressure at the } \\
\text { carina }(\mathrm{mmHg})\end{array}$ & $\begin{array}{l}\text { WSS } \\
\text { LAD } \\
(\mathrm{Pa})\end{array}$ & $\begin{array}{l}\text { WSS } \\
\text { LCX } \\
(\mathrm{Pa})\end{array}$ & $\begin{array}{l}\text { WSS } \\
\text { carina }(\mathrm{Pa})\end{array}$ & $\begin{array}{l}\text { Area of lower } \\
\text { WSS at carina } \\
\left(\mathrm{mm}^{2}\right)\end{array}$ & $\begin{array}{l}\text { WSS opposite } \\
\text { to the carina } \\
\text { (Pa) }\end{array}$ & $\begin{array}{l}\text { Area of lower } \\
\text { WSS opposite } \\
\text { to the carina } \\
\left(\mathrm{mm}^{2}\right)\end{array}$ \\
\hline $\begin{array}{l}\text { Physiological } \\
\text { Model }\end{array}$ & $80^{a}$ & $10.624^{a, b}$ & $12.803^{a}$ & $3.266^{\mathrm{a}}$ & $201^{a, b, c}$ & $2.28^{\mathrm{a}, \mathrm{b}}$ & $186^{\mathrm{a}, \mathrm{b}}$ \\
\hline POT-Side-POT & 79.2 & 9.210 & 10.657 & 2.740 & $508^{b}$ & $2.96^{b}$ & $304^{b}$ \\
\hline KB only & 80.8 & 10.407 & 12.06 & 3.100 & 254 & 3.02 & 214 \\
\hline РОТ-КВ-РОТ & $79.3^{a}$ & $8.415^{\mathrm{a}}$ & $9.729^{a}$ & $2.503^{a}$ & $489^{a}$ & $2.44^{\mathrm{a}}$ & $288^{a}$ \\
\hline POT only & 79.5 & 9.608 & 11.12 & 2.860 & 278 & 2.52 & 201 \\
\hline $2 S K$ & 79.4 & 9.665 & 11.99 & 3.025 & 233 & 2.19 & 218 \\
\hline SKB & 79.3 & $8.897^{b}$ & $9.554^{b}$ & $2.478^{\mathrm{b}}$ & $471^{\mathrm{c}}$ & 3.58 & 265 \\
\hline
\end{tabular}

KB: kissing balloon; POT: proximal optimization technique; 2SK: 2-step kissing; SKB: snuggle kissing balloon; Clear values: $P>0.5,{ }^{a} P=0.03,{ }^{\mathrm{b}} P=0.001$, ${ }^{\mathrm{c}} P=0.003$.

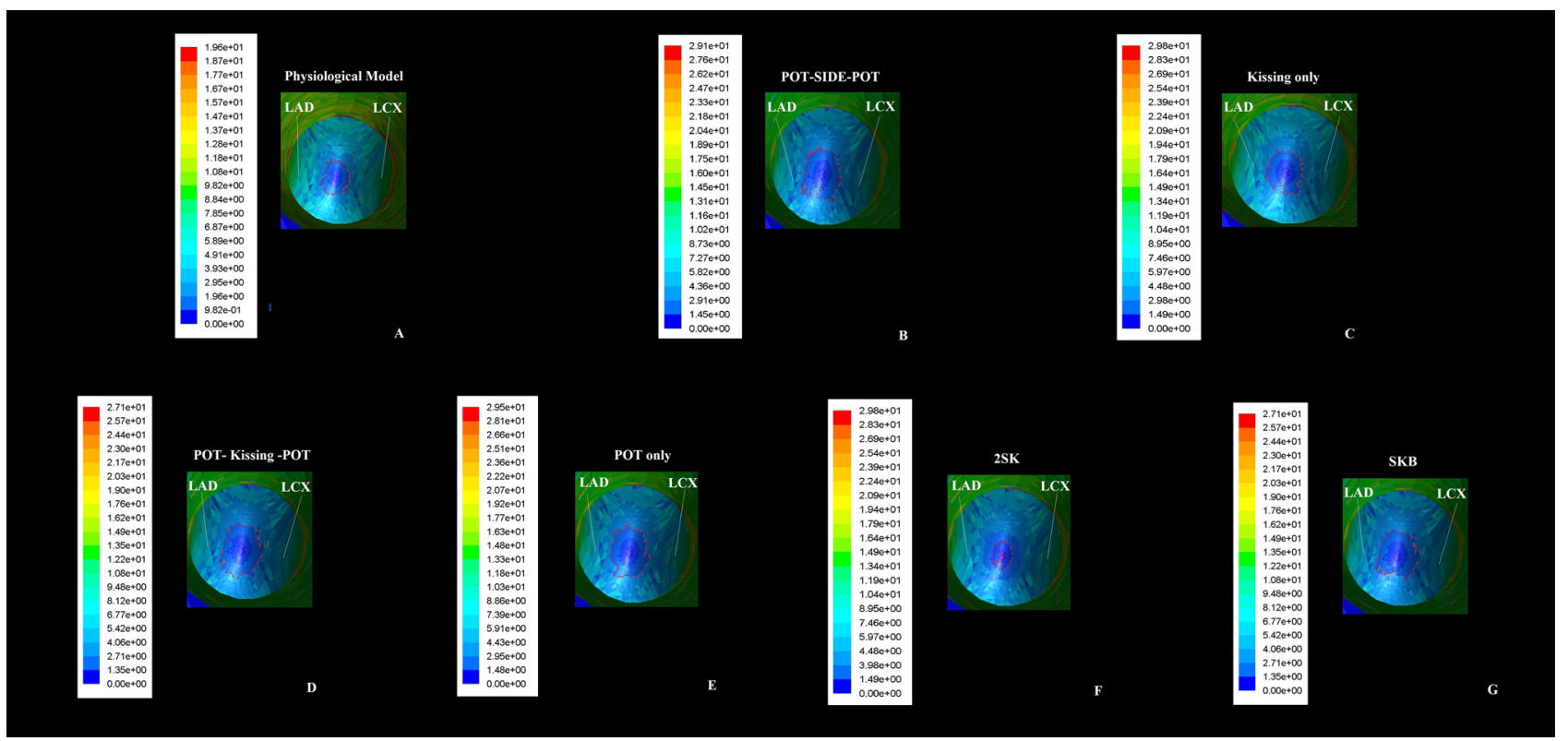

Figure 2: Computed flow dynamic representation of area of lower Wall Shear Stress forces at the carina site using the different post-dilation techniques in Provisional stenting: the area of Wall Shear Stress forces results smaller in kissing balloon and 2-step kissing balloon compared to the others. 
At the wall opposite to the carina, a more physiological profile was obtained only by KB and POT with higher WSS and smaller area of lower WSS, respectively. At the same time, POT-KB-POT, POT-side-POT and SKB, again obtained a worst profile (Table 2, Figure 3).

\section{Culotte stenting analysis}

At the carina, only POT-KB-POT and 2SK resulted in a good profile compared to the physiological model with a smaller surface area of lower WSS at the carina $\left(220 \mathrm{~mm}^{2}\right.$ vs. $202 \mathrm{~mm}^{2}(P<0.03)$, while the KB and POT-Side-POT techniques provided slightly worse results particularly at the carina and ostium of LCX (Table 3, Figure 4).

At the wall opposite to the carina, the SKB, 2SK, and POT$\mathrm{KB}-\mathrm{POT}$ techniques provide the best performance in terms of rheology with a very small area of low WSS and high WSS value in general, while the KB and POT-side-POT techniques resulted again as the worst performers (Table 3, Figure 3).

\section{DISCUSSION}

Our study suggested that from a fluid dynamic point of view, for LM provisional stenting, the POT, KB and
2SK techniques showed similar beneficial impacts on the bifurcation rheology, which were of higher WSS at the opposite wall and smaller surface area of low WSS at the carina, In LM culotte stenting, the POT-KB-POT and 2SK techniques provided slightly better results than the other techniques.

The single stent-provisional and dual stent-culotte techniques are the most widely used techniques to treat LM bifurcation in the real world. These techniques showed good long-term outcomes in both past and recent trials. ${ }^{19-20]}$ How to perform and which is the ideal postdilating technique is still being hotly debated. In the past, the classic final KB inflation constituted the "mantra" of the interventional cardiologist in the optimization of LM stenting. More recently, the POT and its modified techniques such as the POT-Side-POT, 2SK and SKB showed high potential of correcting the KB drawbacks, while achieving a great ostial opening for the SB. Many bench and clinical studies showed that KB restores the MV stent volume, area, and symmetry loss after SB dilation in the bifurcation segment at the cost of some zones of struts malapposition due to the effect and a certain proximal elliptical deformation. ${ }^{[21]}$ On the contrary, POT promoted full proximal stent apposition and conferred a more natural
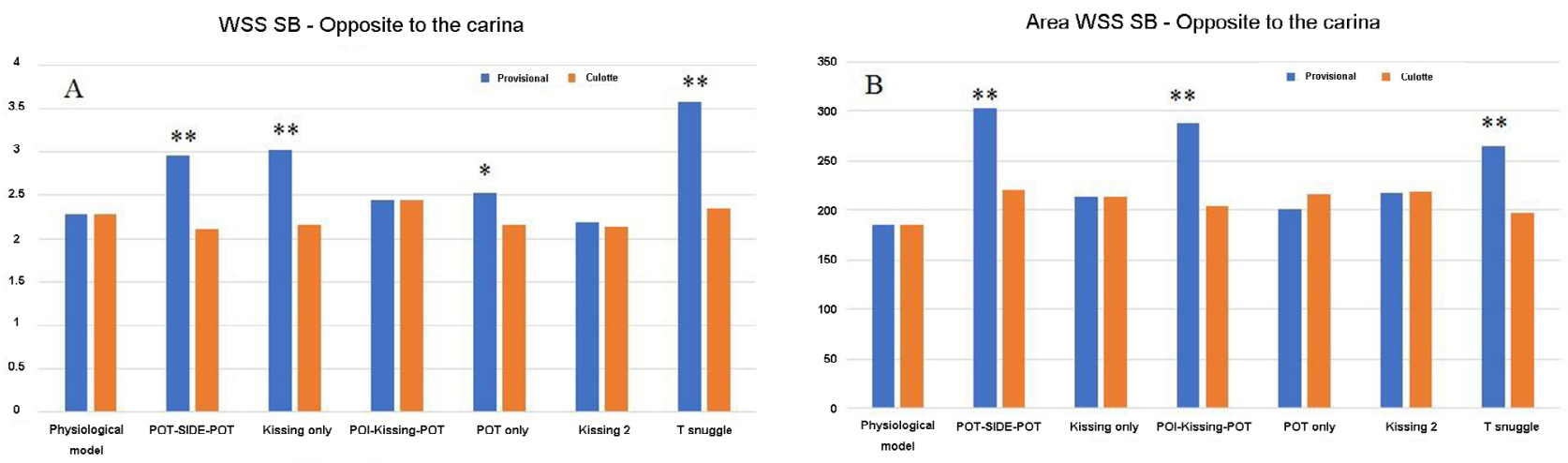

Figure 3: Histograms representation of the comparison of Wall Shear Stress forces value (Panel A) and area of lower Wall Shear Stress forces at the wall opposite to the carina (Panel B) between Provisional (blue bars) and Culotte stenting (orange bars) techniques. ${ }^{*} P<0.05,{ }^{* *} P<0.001$.

\begin{tabular}{|c|c|c|c|c|c|c|c|}
\hline & $\begin{array}{l}\text { Pressure at the } \\
\text { carina }(\mathrm{mmHg})\end{array}$ & $\begin{array}{l}\text { WSS } \\
\text { LAD } \\
(\mathrm{Pa})\end{array}$ & $\begin{array}{l}\text { WSS } \\
\text { LCX } \\
(\mathrm{Pa})\end{array}$ & $\begin{array}{l}\text { WSS } \\
\text { carina }(\mathrm{Pa})\end{array}$ & $\begin{array}{l}\text { Area of lower } \\
\text { WSS at } \\
\text { carina }\left(\mathrm{mm}^{2}\right)\end{array}$ & $\begin{array}{l}\text { WSS opposite } \\
\text { to the carina } \\
(\mathrm{Pa})\end{array}$ & $\begin{array}{l}\text { Area of lower } \\
\text { WSS opposite } \\
\text { to the carina } \\
\left(\mathrm{mm}^{2}\right)\end{array}$ \\
\hline $\begin{array}{l}\text { Physiological } \\
\text { Model }\end{array}$ & 80.0 & $10.624^{a, b}$ & $12.800^{\mathrm{a}, \mathrm{b}}$ & $3.266^{a, b}$ & $208^{a, b}$ & 2.28 & 186 \\
\hline POT-Side-POT & 80.2 & 10.150 & $12.324^{\mathrm{a}}$ & 3.102 & $249^{b}$ & 2.11 & 221 \\
\hline KB only & 80.2 & 10.204 & 12.477 & 3.189 & $236^{a}$ & 2.16 & 214 \\
\hline РОТ-КВ-РОТ & 79.9 & 10.769 & 12.698 & $3.403^{\mathrm{a}}$ & 220 & 2.45 & 205 \\
\hline $2 S K$ & 79.8 & $10.125^{a}$ & 12.355 & 3.279 & 228 & 2.14 & 219 \\
\hline SKB & 79.8 & $9.995^{b}$ & $12.239^{b}$ & $3.104^{c}$ & 209 & 2.35 & 198 \\
\hline
\end{tabular}

KB: kissing balloon; POT: proximal optimization technique; 2SK: 2-step kissing; SKB: snuggle kissing balloon. ${ }^{\mathrm{a}} P=0.03,{ }^{\mathrm{b}} P=0.001$. 


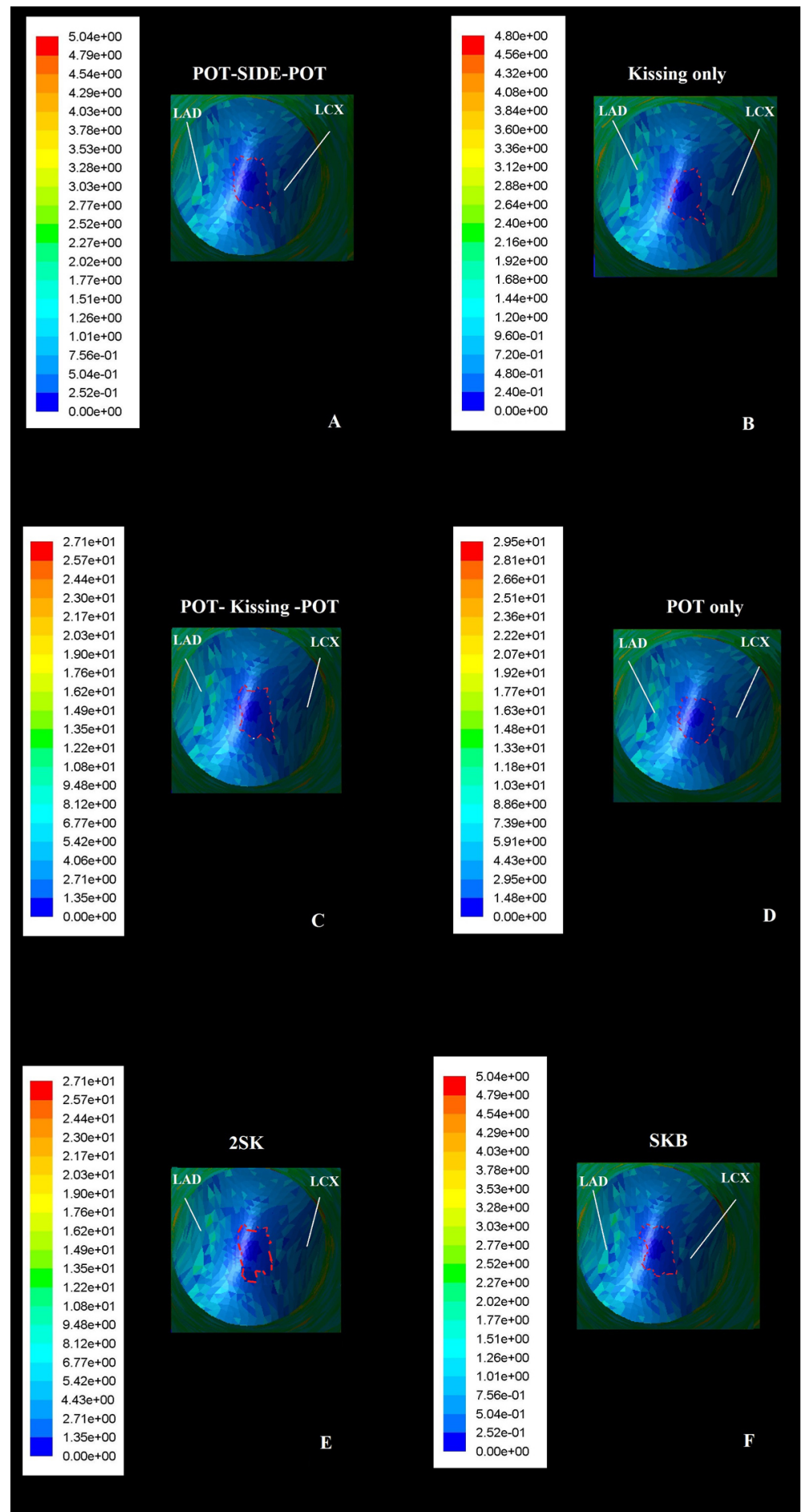

Figure 4: Computed flow dynamic representation of area of lower Wall Shear Stress forces at the carina site using the different post-dilation techniques in Culotte stenting: the area of Wall Shear Stress forces results smaller in POT-kissing balloon-POT and 2-steps kissing balloon compared to the others.

circular shape to the proximal segment of the MV. ${ }^{[6]}$ POT also increased the size of opening of the SB ostium and by that, facilitated a distal wire re-crossing, independent of which stent type was used. ${ }^{[2]}$

Intriguingly in our study, neither POT (only in provisional stenting) nor KB (only in dual stenting) were able to increase significantly the WSS at both carina and the wall opposite to the carina, compared to the novel techniques. In provisional stenting, $\mathrm{KB}$ and its modifications, the $2 \mathrm{SK}$, performed better than POT at the carina site, while at the wall opposite to the carina, POT provided smaller area of lower WSS compared to all the other techniques. On the other hand, after culotte stenting, POT modifications, the so-called POT-KB-POT and 2SK, performed better than the classical KB, particularly at the carina and wall opposite 
to the carina, where the WSS were much lower with $\mathrm{KB}$ only or with POT-side-POT.

In the past, other studies could explain these findings and at least partially confirmed the bench study results. ${ }^{[5,6]}$ POT had the maximum impact only on the proximal part of the MV and opened the struts of the SB, while at the wall of the SB opposite to the carina, POT increased the apposition of struts but not at the carina itself.

In our study, the technique implying simultaneous or sequential dilation of MV and SB increased WSS at the carina and at the wall opposite to the carina as well. However, in dual stenting, the sequential technique was not beneficial as much as when it was associated with POT. Indeed, KB only induced a bottleneck effect with lower WSS at the carina and this problem could only be corrected with a second POT. These observations suggest that a better strut apposition rather than a more complete coverage induced a smaller area of lower WSS, which produced a beneficial effect in respect to restenosis and more importantly thrombosis. As matter of fact, narrow strut spacing leads to larger areas of adverse low WSS, an effect which in part could be mitigated by reducing the struts thickness and size. ${ }^{[23]}$ In our study, the conclusion could be made that the beneficial mechanism of POT, 2SK and $\mathrm{KB}$ were more likely due to better strut apposition rather than homogenous strut coverage.

\section{Limitations}

Some confounders would be different and multiple including the particular stenting technique considered in our study, obviously different from DK-crush or T-stent, the pressure of inflation and deployment, the angle of the carina that is a mean angle driven from the anatomical findings of our standard population, the diameter of the model that again reflects the mean vessel diameters of our population. Moreover, our study takes into account an ideal left main model. The artery has been considered non-compliant, straight and stationary. However, coronary artery perfusion is mainly diastolic and previous studies have already demonstrated that myocardial motion has a negligible effect on blood flow distribution on the arterial tree. Our model considered an optimal stent deployment without residual stenosis despite use in daily clinical practice, the different angles, the amount and circumferential extent of the calcium, the length of the respective lesion, and many other parameters have an obvious impact on the implantation technique and outcomes. Moreover, imposed hemodynamic conditions assume that the patient was hemodynamically stable. Other limitations of the study are that we did not evaluate the time averaged wall shear stress (TAWWS), oscillatory index (OSI) and the relative residence time, which had a recognized role in the treatment of coronary artery stenosis.

\section{CONCLUSIONS}

Different post-dilation techniques analyzed by CFD have a different impact on rheolysis of LM bifurcation with a more significant effect after provisional stenting, as compared to culotte stenting.

Although not transferrable to clinical practice, our study substantially confirmed and enhanced the clinical value of recently proposed modification of POT and $\mathrm{KB}$ in LM stenting such as $2 \mathrm{SK}$ in provisional and POT-KB-POT in culotte stenting, suggesting a good strut apposition as the basis of maintaining a beneficial bifurcation rheology. The apparent negative or neutral impact on bifurcation rheology by the other techniques should probably be viewed in the light of the positive effects on stent apposition and geometry using these two stenting techniques. Whether these findings would be confirmed using other stenting techniques and in anatomical scenario different from LM, should be tested in further studies. However, clinical trials, although difficult to conceive, are needed to assess the real contribution of all these techniques on the long-term outcomes of LM stenting.

\section{Conflict of Interest}

None of the other authors have identified a conflict of interest.

\section{REFERENCES}

1. Murasato Y, Finet G, Foin N. Final kissing balloon inflation: the whole story. EuroIntervention 2015; 11: V81-5

2. Foin N, Secco GG, Ghilencea L, Krams R, Di Mario C. Final proximal post-dilatation is necessary after kissing balloon in bifurcation stenting. EuroIntervention 2011; 7: 597-604.

3. Biondi-Zoccai G, Sheiban I, De Servi S, Tamburino C, Sangiorgi G, Romagnoli E. To kiss or not to kiss? Impact of final kissing-balloon inflation on early and long-term results of percutaneous coronary intervention for bifurcation lesions. Heart Vessels 2014; 29: 732-42.

4. Finet G, Derimay F, Motreff P, Guerin P, Pilet P, Ohayon J, et al. Comparative Analysis of Sequential Proximal Optimizing Technique Versus Kissing Balloon Inflation Technique in Provisional Bifurcation Stenting: Fractal Coronary Bifurcation Bench Test. JACC Cardiovasc Interv 2015; 8: 1308-17.

5. Derimay F, Souteyrand G, Motreff P, Guerin P, Pilet P, Ohayon J, et al. Sequential Proximal Optimizing Technique in Provisional Bifurcation Stenting With Everolimus-Eluting Bioresorbable Vascular Scaffold: Fractal Coronary Bifurcation Bench for Comparative Test Between Absorb and XIENCE Xpedition. JACC Cardiovasc Interv 2016; 9: 1397-406.

6. MurasatoY, Iwasaki K, Yamamoto T, Yagi T, Hikichi Y, Suematsu Y, et al. Optimal kissing balloon inflation after single-stent deployment in a coronary bifurcation model. EuroIntervention 2014; 10: 934-41.

7. Foin N, Torii R, Mortier P, De Beule M, Viceconte N, Chan PH, et al. Kissing balloon or sequential dilation of the side branch and main vessel for provisional stenting of bifurcations: lessons from micro-computed tomography and computational simulations. JACC Cardiovasc Interv 2012; 5: 47-56. 
8. Seth A, Sengottuvelu G, Ravisekar V. Salvage of Side Branch by Provisional "TAP Technique" Using AbsorbTM Bioresorbable Vascular Scaffolds for Bifurcation Lesions: First Case Reports with Technical Considerations. Catheter Cardio Inte 2014; 84: 55-61.

9. Zuin M, Rigatelli G, Faggian G, Roncon L. Mathematics and Cardiovascular Interventions: Role of the Finite Element Modeling in Clinical Decision Making. JACC Cardiovasc Interv 2016; 9: 507-8.

10. Finet G, Gilard M, Perrenot B, Rioufol G, Motreff P, Gavit L, et al. Fractal geometry of arterial coronary bifurcations: a quantitative coronary angiography and intravascular ultrasound analysis. EuroIntervention 2008; 3: 490-8.

11. Lassen JF, Holm NR, Banning A, Burzotta F, Lefèvre T, Chieffo A, et al. Percutaneous coronary intervention for coronary bifurcation disease: 11th consensus document from the European Bifurcation Club. EuroIntervention 2016; 12: 38-46.

12. Theodorakakos A, Gavaises M, Andriotis A, Zifan A, Liatsis P, Pantos I, et al. Simulation of cardiac motion on non-Newtonian, pulsating flow development in the human left anterior descending coronary artery. Phys Med Biol 2008; 53: 4875-9.

13. Nichols WW, O'Rourke MF. The nature of flow of a liquid. In: McDonald's Blood Flow in Arteries: Theoretical, Experimental and Clinical Principles. 4th ed. London, UK: Arnold; 1998: pp. 11-53.

14. Karino T, Goldsmith HL, Motomiya M, Mabuchi S, Sohara Y. Flow patterns in vessels of simple and complex geometries. Ann N Y Acad Sci 1987; 516: 422-41.

15. Zimarino M, Corazzini A, Ricci F, Di Nicola M, De Caterina R. Late thrombosis after double versus single drug-eluting stent in the treatment of coronary bifurcations: a meta-analysis of randomized and observational Studies. JACC CardiovascInterv 2013; 6: 687-95.

16. Wentzel JJ, Chatzizisis YS, Gijsen FJ, Giannoglou GD, Feldman CL, Stone $\mathrm{PH}$. Endothelial shear stress in the evolution of coronary atherosclerotic plaque and vascular remodeling: current understanding and remaining questions. Cardiovasc Res 2012; 96: 234-43.

17. Krams R, Wentzel JJ, Oomen JA, Vinke R, Schuurbiers JC, de Feyter PJ, et al. Evaluation of endothelial shear stress and 3D geometry as factors determining the development of atherosclerosis and remodeling in human coronary arteries in vivo. Combining $3 \mathrm{D}$ reconstruction from angiography and IVUS (ANGUS) with computational fluid dynamics. Arterioscler Thromb Vasc Biol 1997; 17: 2061-5.

18. Samady H, Eshtehardi P, McDaniel MC, Suo J, Dhawan SS, Maynard C, et al. Coronary artery wall shear stress is associated with progression and transformation of atherosclerotic plaque and arterial remodeling in patients with coronary artery disease. Circulation 2011; 124: 779-88.

19. D’Ascenzo F, Iannaccone M, Giordana F, Chieffo A, Connor SO, Napp LC, et al. Provisional vs. two-stent technique for unprotected left main coronary artery disease after ten years follow up: A propensity matched analysis. Int J Cardiol 2016; 211: 37-42.

20. Tiroch K, Mehilli J, Byrne RA, Schulz S, Massberg S, Laugwitz KL, et al; ISAR-LEFT MAIN Study Investigators. Impact of coronary anatomy and stenting technique on long-term outcome after drug-eluting stent implantation for unprotected left main coronary artery disease. JACC Cardiovasc Interv 2014; 7: 29-36.

21. Rahman S, Leesar T, Cilingiroglu M, Effat M, Arif I, Helmy T, et al. Impact of kissing balloon inflation on the main vessel stent volume, area, and symmetry after side-branch dilation in patients with coronary bifurcation lesions: a serial volumetric intravascular ultrasound study. JACC Cardiovasc Interv 2013; 6: 923-31.

22. Derimay F, Souteyrand G, Motreff P, Rioufol G, Finet G. Influence of platform design of six different drug-eluting stents in provisional coronary bifurcation stenting by rePOT sequence: a comparative bench analysis. EuroIntervention 2017; 13: e1092-5.

23. Beier S, Ormiston J, Webster M, Cater J, Norris S, Medrano-Gracia P, Young A, Cowan B. Hemodynamics in Idealized Stented Coronary Arteries: Important Stent Design Considerations. Ann Biomed Eng 2016; 44: 315-29.

How to cite this article: Rigatelli G, Dell'Avvocata F, Zuin M, Giatti S, Duong K, Pham T, et al. Comparative computed flow dynamic analysis of different optimization techniques in left main either provisional or culotte stenting. J Transl Intern Med 2017; 5: 205-12. 